\title{
Process Outgrowth of Oligodendrocytes Is Promoted by Interaction of Fyn Kinase with the Cytoskeletal Protein Tau
}

\author{
Corinna Klein, ${ }^{1}$ Eva-Maria Krämer, ${ }^{1}$ Anne-Marie Cardine, ${ }^{2}$ Burkhardt Schraven, ${ }^{2}$ Roland Brandt, ${ }^{1}$ and \\ Jacqueline Trotter $^{1}$
}

Departments of ${ }^{1}$ Neurobiology and $2 /$ mmunology, University of Heidelberg, 69120 Heidelberg, Germany

Fyn kinase plays an important role during myelination and has been shown to promote morphological differentiation of cultured oligodendrocytes. We analyzed the downstream targets of Fyn kinase in oligodendrocytes. Because process outgrowth and wrapping of axons involve cytoskeletal rearrangement, we focused on cytoskeletal proteins linked to Fyn. Here we demonstrate that Fyn binds to the cytoskeletal proteins Tau and $\alpha$-Tubulin in oligodendrocytes. Tau interacts with the Fyn $\mathrm{SH} 3$ domain whereas $\alpha$-Tubulin binds to the Fyn $\mathrm{SH}_{2}$ and $\mathrm{SH} 3$ domains. To study the function of the Fyn-Tau interaction in oligodendrocytes, we designed a Tau deletion mutant that would compete with endogenous Tau-Fyn binding in transfected cells. The mutant Tau protein binds to the Fyn SH3 domain but lacks the microtubuli interaction domain and thus cannot bind to microtubuli. In the presence of the mutant Tau protein, a reduction of the process number and process length in oligodendroglial cells was observed. This effect is likely to be caused by interference with the Fyn-Tau-microtubuli cascade rather than inactivation of the kinase, because Fyn bound to the mutant Tau retains activity. A similar inhibition of process outgrowth was observed when oliogodendroglial cells were cultured in the presence of Fumonisin B1, an inhibitor of sphingolipid synthesis that prevents the formation of rafts. Because ligation of the cell adhesion molecule F3 on oligodendrocytes leads to activation of Fyn kinase localized in rafts, these findings suggest that recruitment of Tau and Tubulin to activated Fyn kinase in rafts is an important step in the initiation of myelination.

Key words: myelination; oligodendrocytes; Fyn kinase; cytoskeleton; Tau; glycosphingolipid-rich rafts
The myelination of axons by oligodendrocytes involves the coordinated recognition of the axonal surface, ensheathment of the axonal process, and ultimately compaction of the wrappings of oligodendroglial membrane to generate the myelin sheath. The interplay of the adhesion molecules expressed by oligodendrocytes and axons as well as the downstream signal transduction cascades mediating these complex cellular interactions still remain primarily unelucidated (Pedraza et al., 2001).

Substantial evidence exists that Fyn expressed by oligodendrocytes plays an important role in myelination. Mice deficient for Fyn kinase are hypomyelinated (Umemori et al., 1994; Sperber and McMorris, 2001; Sperber et al., 2001). In addition, knock-in mice expressing a kinase-defective Fyn protein that cannot be activated because of a mutation in the ATP-binding site of Fyn show severe myelination defects (Sperber et al., 2001). Inhibition of the Fyn activity in cultured oligodendrocytes using kinase inhibitors or dominant negative Fyn constructs inhibited the process outgrowth of the cells (Osterhout et al., 1999). We have shown that in oligodendrocytes [as in neurons (Zisch et al., 1995)] the F3 adhesion molecule is complexed to the Src-family tyrosine kinase Fyn and that this association takes place within glycosphingolipid (gsl)/cholesterol-rich microdomains (Kramer et al., 1999), generally called rafts (Simons and Ikonen, 1997). Antibody-mediated cross-linking of F3 on the cell surface of the

Received July 19, 2001; revised Oct. 3, 2001; accepted Nov. 14, 2001.

The Deutsche Forschungsgemeinschaft is thanked for financial support (Grants SFB 317 and SFB 488 to J.T., SFB 488 to R.B.; Graduate Kolleg Molecular and Cellular Neurobiology to C.K.).

Correspondence should be addressed to Jacqueline Trotter, Department of Neurobiology, University of Heidelberg, Im Neuenheimer Feld 324, 69120 Heidelberg, Germany. E-mail: jtrotter@sun0.urz.uni-heidelberg.de.

Copyright (C) 2002 Society for Neuroscience $\quad 0270-6474 / 02 / 220698-10 \$ 15.00 / 0$ oligodendroglial cell line Oli-neu leads to the activation of Fyn kinase exclusively within the rafts (Kramer et al., 1999). All of these experiments raise the question of the identity of downstream targets of Fyn. Fyn shares a common domain structure with all nine Src-family members, including the protein binding domains SH2 (binding to phosphorylated tyrosine moieties) and SH3 [recognizing a core consensus sequence of PXXP (for review, see Thomas and Brugge, 1997)]. Because process outgrowth involves cytoskeletal rearrangements, Fyn kinase is likely to be linked directly or indirectly to the cell cytoskeleton.

The microtubule-associated protein Tau interacts with components of the neuronal plasma membrane in addition to microtubules (Brandt et al., 1995; Maas et al., 2000). Tau induces microtubule assembly and bundle formation leading to process formation (for review, see Brandt, 1996). In a neuroblastoma cell line, Tau has been shown to associate with the Fyn SH3 domain (Lee et al., 1998). Tau is expressed primarily by neurons but is expressed additionally by oligodendrocytes in vivo and in vitro (LoPresti et al., 1995, 2001; Muller et al., 1997; Richter-Landsberg and Gorath, 1999; Richter-Landsberg, 2000; Song et al., 2001b).

In this report we show that in oligodendrocytes Fyn is associated with Tau and $\alpha$-Tubulin. Overexpression of a Tau deletion protein in cultured oligodendrocytes reduces the length and number of processes, most likely by disrupting Fyn-Tau binding. Inhibition of gsl synthesis and consequently raft formation similarly inhibits process outgrowth of oligodendrocytes. These results demonstrate that the interaction of Fyn and Tau is an important component of oligodendroglial process growth. Furthermore, activation of raft-associated Fyn may be a critical factor initiating the recruitment and rearrangement of cytoskeletal components such as Tau and Tubulin to the site of process outgrowth. 


\section{MATERIALS AND METHODS}

Animals. NMRI mice of both sexes were obtained from the central animal facilities of the University of Heidelberg.

Materials and antibodies. L- $\left[{ }^{35} \mathrm{~S}\right]-\mathrm{Met} / \mathrm{Cys}$ in vitro labeling $\operatorname{mix}, \gamma\left[{ }^{32} \mathrm{P}\right]-$ ATP, and ECL reagents were from Amersham Biosciences (Braunschweig, Germany); human recombinant PDGF(AA) and bFGF were from TEBU (Frankfurt, Germany); Triton X-100, NP-40, and Nadeoxycholate were from Sigma (Deisenhofen, Germany); Protein A-Sepharose CL4B was from Amersham Biosciences (Freiburg, Germany); Bradford reagent for protein assays was from Bio-Rad (München, Germany); and polyvinylidene difluoride (PVDF) membrane was from Millipore (Bedford, MA).

The following rabbit polyclonal antibodies were used: against F3 [Ig-fraction of a serum raised against the N-terminal F3 peptide (Koch et al., 1997)], against Fyn and Lyn (Santa Cruz, Heidelberg, Germany), and Tau [pNtau, raised against a recombinant human Tau comprising amino acids (aa) 1-223]. The following monoclonal antibodies were used: murine monoclonal antibody against Fyn (BD Transduction Laboratories, Heidelberg, Germany), murine antibodies against $\alpha$-Tubulin (DM1A; Sigma, Munich, Germany) and against the Myc epitope, clone 9E10 (Sigma), murine antibodies against Tau [Tau-5, BD Bioscience, PharMingen, Heidelberg, Germany; Tau-1 (Binder et al., 1985)], and murine monoclonal antibody $\mathrm{O} 4$ recognizing a late stage of oligodendroglial progenitors and mature oligodendrocytes (Sommer and Schachner, 1981; Trotter and Schachner, 1989). Secondary antibodies were from Dianova (Hamburg, Germany).

Primary cell cultures and metabolic labeling. Primary cultures of oligodendrocytes were prepared from embryonic day 14-16 mice as described (Sontheimer et al., 1989; Trotter et al., 1989). In short, oligodendrocytes growing on top of astrocyte monolayers were shaken off and plated in modified Sato medium (Trotter et al., 1989) containing 1\% horse serum (HS) on poly-L-lysine-coated dishes. To promote survival of the cells, 10 $\mathrm{ng} / \mathrm{ml}$ human recombinant platelet-derived growth factor (AA) and 5 $\mathrm{ng} / \mathrm{ml}$ basic fibroblast growth factor were added immediately after plating and after $24 \mathrm{hr}$ in vitro. Oligodendrocytes were kept for $5 \mathrm{~d}$ in vitro without additional growth factors before harvesting. The resulting population is enriched for differentiated oligodendrocytes but contains a fraction of progenitor cells (Trotter and Schachner, 1989). The cell line Oli-neu (Jung et al., 1995) was cultured in Sato medium containing 1\% HS. For metabolic labeling, primary oligodendrocytes or transient transfected cells were incubated for $1 \mathrm{hr}$ in $\mathrm{SO}_{4} / \mathrm{Met} / \mathrm{Cys}$-free DMEM and further incubated for $4 \mathrm{hr}$ with $100 \mu \mathrm{Ci} / \mathrm{ml} \mathrm{L}-\left[{ }^{35} \mathrm{~S}\right] \mathrm{Met} / \mathrm{Cys}$. All samples were analyzed by SDS-PAGE, and radioactive protein bands were detected by a Phosphoimager (Fuji Bas 1000; Fuji Medical Systems USA Inc., Stanford, CA).

Immunofluorescence. For double staining of primary oligodendrocytes with the oligodendroglial markers O4, myelin associated glycoprotein (MAG), AN2, and Tau or Fyn, cells on coverslips were fixed in $4 \%$ paraformaldehyde, blocked, and incubated with the primary antibody in blocking solution (1\% BSA/PBS) for $30 \mathrm{~min}$. The cells were permeabilized for $10 \mathrm{~min}$ with $0.1 \%$ Triton $\mathrm{X}-100$, fixed for $10 \mathrm{~min}$, and incubated with Tau or Fyn antibodies and subsequently with labeled secondary antibodies and mounted in Moviol. Cells were analyzed by fluorescence light microscopy (Axiophot; Zeiss, Göttingen, Germany).

Preparation of detergent extracts and sucrose density gradient centrifugation. Detergent extracts were prepared as described (Kramer et al., 1999). In brief, primary oligodendrocytes $\left(2-3 \times 10^{6}\right)$ were suspended at $4^{\circ} \mathrm{C}$ in $0.5 \mathrm{ml}$ extraction buffer: $150 \mathrm{~mm} \mathrm{NaCl}, 80 \mathrm{mM} \mathrm{Na}_{2} \mathrm{HPO}_{4} 2 \times \mathrm{H}_{2} \mathrm{O}, 17 \mathrm{~mm}$ $\mathrm{NaH}_{2} \mathrm{PO}_{4} \times \mathrm{H}_{2} \mathrm{O}, \mathrm{pH} 7.2,1 \mathrm{~mm} \mathrm{PMSF}$, and 2\% NP-40 (PBS/NP-40). The extracts were shaken for $30 \mathrm{~min}$ at $4^{\circ} \mathrm{C}$. Detergent extracts were adjusted to $40 \%$ sucrose by adding equal volumes of $80 \%$ sucrose in PBS/NP-40 and loaded into an ultracentrifuge tube. A step gradient of 30 and $10 \%$ or a continuous gradient of 30 to $5 \%$ sucrose was layered on top of the lysate. Gradients were centrifuged for $12 \mathrm{hr}$ at 35,000 rpm at $4^{\circ} \mathrm{C}$ in a Beckman SW 40 TI rotor or Beckman SW 60 TI rotor $(218,000 \times g)$. The floating fraction (raft fraction) and the bottom fractions (non-raft fraction) were harvested. Light gradient fractions containing floating GPI-anchored proteins, glycosphingolipids, and cholesterol (rafts) were collected, diluted with $\mathrm{ddH}_{2} \mathrm{O}$, and pelleted for $1 \mathrm{hr}$ at $218,000 \times g$ and $4^{\circ} \mathrm{C}$. Isolated rafts were subjected to SDS-PAGE, immunoblotting, and immunoprecipitation.

Immunoblotting. Proteins were blotted onto PVDF membrane (Amersham Biosciences), which was incubated in $4 \%$ milk powder $/ 0.05 \%$ Tween in PBS. Proteins were detected by incubation with primary antibodies overnight at $4^{\circ} \mathrm{C}$. The blots were incubated with a second anti-species antibody conjugated with HRP for 30-60 min at room temperature. The blots were developed with ECL reagents (Amersham Biosciences) according to the manufacturer's instructions.

In some cases, membranes were stripped with $100 \mathrm{~mm}$ glycine, $\mathrm{pH} 2$, for $30 \mathrm{~min}$, blocked, and reprobed with antibodies.

Immunoprecipitation. Isolated raft fractions and non-raft fractions were resuspended in $0.5 \mathrm{ml} \mathrm{PBS} / \mathrm{NP}-40$ buffer, precleared with protein A-Sepharose, incubated with antibodies overnight at $4^{\circ} \mathrm{C}$ on a head-overtail rotator for $2 \mathrm{hr}$ with protein A-Sepharose, and washed three times under stringent conditions in RIPA-buffer (50 mM Tris/ HCl, pH 7.4, $1 \%$ Triton X-100, $1 \%$ Na-deoxycholate, $0.1 \%$ SDS, $1 \mathrm{~mm}$ dithioerythnol) containing phosphatase inhibitors $\left(100 \mu \mathrm{M} \mathrm{Na} \mathrm{VO}_{4}, 10 \mathrm{~mm} \mathrm{NaF}\right)$ and once with PBS. The immunoprecipitations were subjected to SDS-PAGE and immunoblotting.

In vitro kinase assay. Immune complexes were resuspended in $50 \mu \mathrm{l}$ kinase buffer (20 mM HEPES, pH 7.4, $5 \mathrm{~mm} \mathrm{MgCl}_{2}, 1 \mathrm{mM} \mathrm{MnCl}_{2}, 100 \mu \mathrm{M}$ $\left.\mathrm{Na}_{3} \mathrm{VO}_{4}\right)$ and incubated with $2 \mu \mathrm{Ci} \gamma\left[{ }^{32} \mathrm{P}\right]-\mathrm{ATP}$ for $30 \mathrm{~min}$ at $37^{\circ} \mathrm{C}$. The samples were washed and subjected to SDS-PAGE and autoradiography.

Expression of glutathione S-transferase-Fyn constructs and binding assay. Glutathione $S$-transferase (GST)-Fyn-SH3 cDNA and GST-Fyn-SH2 cDNA were prepared as described (Marie-Cardine et al., 1995), GSTAmphiphysin-SH3 was kindly provided by Dr. A. Schmidt (CNRS, Paris, France). GST fusion proteins were prepared and purified as described (Smith and Johnson, 1988). For precipitation of interacting partners, primary oligodendrocytes were lysed in PBS/NP-40 and shaken for 30 min at $4^{\circ} \mathrm{C}$. To free the postnuclear lysates from proteins binding unspecifically to GST Sepharose beads, samples were incubated with GSTSepharose beads for $1 \mathrm{hr}$ at $4^{\circ} \mathrm{C}$ before incubation with GST-Fyn-SH3, GST-Fyn-SH2 or GST-Amphiphysin-SH3 Sepharose beads overnight at $4^{\circ} \mathrm{C}$ (preclear). The precipitates were washed with RIPA buffer and subjected to SDS-Page and immunoblotting.

Construction of Tau deletion mutants. Eukaryotic expression plasmids were constructed in the pCMV vector (Invitrogen, Groningen, The Netherlands). Inserts for all plasmids were obtained by PCR using cDNA from adult rat brain. PCR primers contained restriction sites, a Kozak sequence, and stop codons as needed. A myc tag was added to the amino terminal end. The following oligonucleotides were used to generate the deletion constructs: Tau forward: GCGAATTCAAAGACATGGCTGAACCCCGCCAGGAGTTTGACATGGCTGAACCCCGCCAGGAG; Tau reverse +PXXP: CGCAAGCTTCTAACTGGCAGACGGTGAC TTAGG; Tau reverse -PXXP: CGCAAGCTTCTAAACCACTGCCACCTTTTTGGGCTC.

The constructs were verified by sequencing. Plasmids prepared for the studies were as follows: pCMV + PXXP: myc tag and adult rat Tau from amino acid 1-227 containing the SH3 binding motif for Fyn; pCMV - PXXP: myc tag and adult rat Tau from amino acid 1-223 lacking the SH3 binding motif for Fyn.

Transfection and analysis of transfected cells. Oli-neu cells (Jung et al., $1995)$ were released from the culture dishes with trypsin. Primary oligodendrocytes were transfected directly after shaking. For each electroporation, $1.5 \times 10^{6}$ Oli-neu cells or 3-4 $\times 10^{6}$ primary oligodendrocytes were used. Fifteen micrograms of DNA of Tau plasmids were used in each electroporation. Tau plasmids were cotransfected with the pCMVenhanced green fluorescent protein (EGFP) plasmid (2 $\mu \mathrm{g}$ DNA; Clontech Heidelberg, Germany) to control electroporation and identify positive cells. Transient transfected cells were analyzed live using an inverted fluorescent microscope (Leitz, DM IRB; Leica, Bensheim, Germany) with an attached digital camera (Quantics Photometrics; Visitron Systems, Puckheim, Germany) and the software IPlab 3.2.2. (Scananalytics, Inc., Visitron Systems). The number of processes per cell and the process length were measured for Oli-neu cells and primary oligodendrocytes. Processes longer than half the diameter of the cell soma were included in the measurements. In each experiment, 50-100 EGFP-positive Oli-neu cells or 30-50 EGFP-positive primary oligodendrocytes were analyzed. Three individual experiments per cell type were performed. The data were pooled, and a nonparametric Mann-Whitney rank sum test was applied to analyze the results because it cannot be assumed that the number and length of cellular processes follow a Gaussian distribution.

Inhibition of sphingolipid synthesis in Oli-neu cells with Fumonisin B1. Oli-neu cells were incubated for up to $5 \mathrm{~d}$ with $50 \mu \mathrm{M}$ Fumonisin B1 (FB1) (Sigma). Cells were passaged on the third day and incubated in the presence of FB1 for 2 more days. For recovery, Oli-neu cells, after $5 \mathrm{~d}$ of culture with FB1, were washed twice with Sato $1 \%$ HS and incubated for 
A
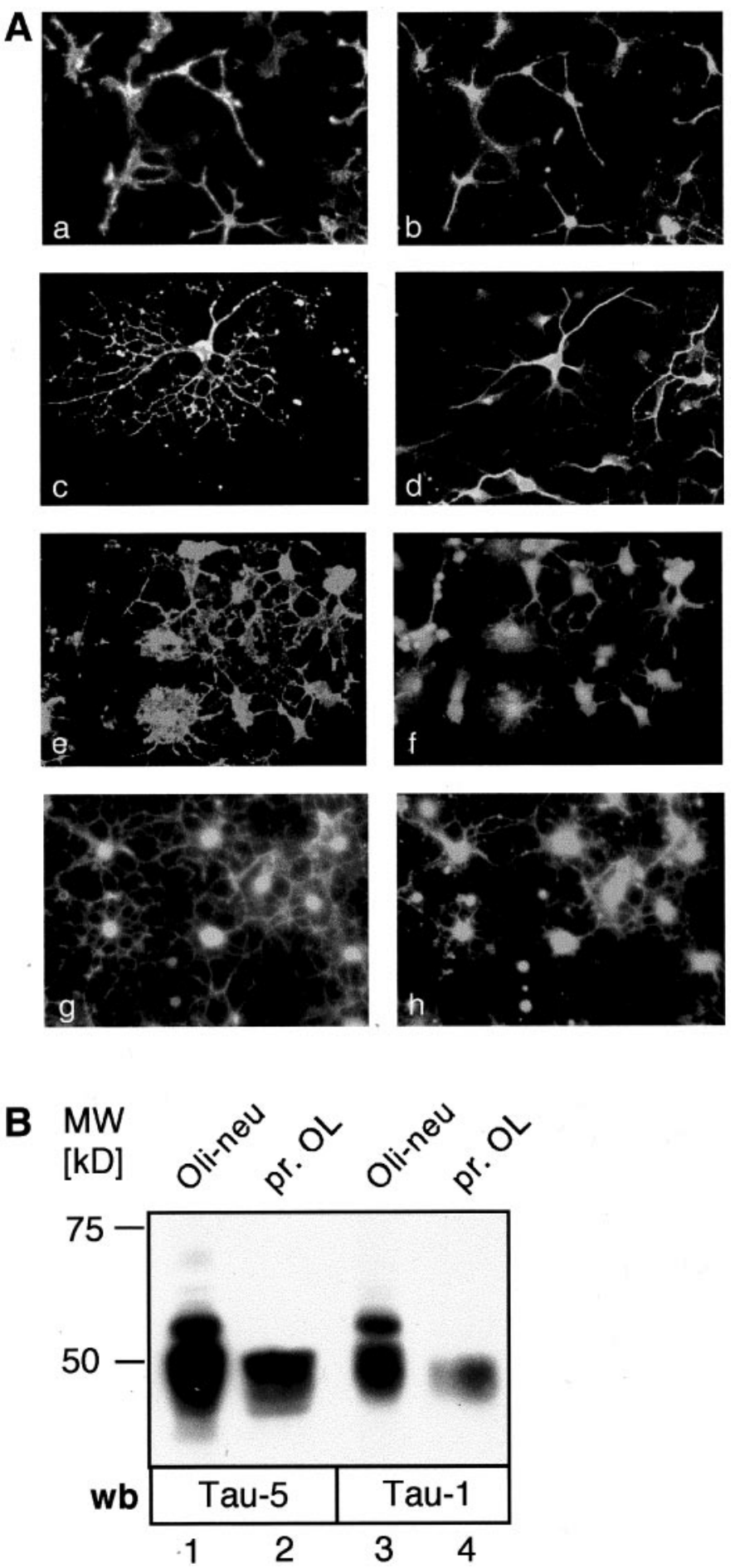

Figure 1. Cultured oligodendrocytes express Tau. A, Immunofluorescence staining. Primary oligodendrocytes were stained with antibodies to oligodendroglial markers and Tau $(a-f)$ or with Fyn and Tau $(g, h)$. All AN2-positive oligodendrocyte precursor cells $(a)$ stain for Tau $(b)$. Tau is expressed in the cell soma as well as in the processes. Primary oligodendrocytes were costained with antibodies to the oligodendroglial markers $\mathrm{O} 4(c)$ or MAG $(e)$ and Tau $(d, f)$. Cell somata as well as large membrane processes are positive for Tau, whereas the tips of very small processes are unstained. $\mathrm{O} 4$ and MAG staining are distributed all over the cell surface including small processes and membrane protrusions. $B$, Western blot analysis. Both primary oligodendrocytes $(\mathrm{pr} . O L)$ and the precursor cell line Oli-neu express Tau. Cell lysates of Oli-neu cells (lanes 1,3) and primary oligodendrocytes (lanes 2, 4) were resolved by SDS-PAGE and immunoblotted with the antibodies Tau-5 (lanes 1,2) recognizing an
2 additional days. Cells were fixed with $2.5 \%$ glutaraldehyde for $1 \mathrm{hr}$ and stained with toluidine blue to visualize processes.

Lipid analysis. Primary oligodendrocytes were treated with $50 \mu \mathrm{M}$ FB1 directly after the shake for $5 \mathrm{~d}$ and subjected to continuous sucrose density gradient separation (see above). As controls, untreated primary oligodendrocytes were analyzed. From each gradient fraction lipids were extracted (Bligh and Dyer, 1957), and dried samples were dissolved in $10-20 \mu \mathrm{l}$ of chloroform/methanol $(1: 1, \mathrm{w} / \mathrm{v})$ and spotted on activated Silica Gel $60 \mathrm{~F}_{254}$ plates (Merck, Darmstadt, Germany). After resolution of the lipids in chloroform/methanol/ $\mathrm{H}_{2} \mathrm{O}(65: 25: 4, \mathrm{v} / \mathrm{v})$, the plates were air dried and lipids were visualized after exposure of the plates to $10 \%$ sulfuric acid, 5\% methanol, and charring.

\section{RESULTS}

\section{Oligodendrocytes in culture express Tau and Fyn}

Primary oligodendrocyte cultures enriched in mature oligodendrocytes were costained with antibodies to the oligodendroglial markers AN2/NG2, O4, and MAG, and pNTau antibody (Fig. 1A). All AN2/NG2-positive oligodendrocyte progenitor cells were strongly Tau positive (Fig. $1 A, a, b)$. Approximately $70 \%$ of all O4-positive oligodendrocytes were stained with pNTau (Fig. 1A,c,d). Cell somata as well as primary membrane processes were strongly Tau positive, whereas very small processes and the process tips were less stained. The same distribution was observed when the cultures were stained with antibodies to MAG and pNTau (Fig. $1 A, e, f)$. These results are in agreement with previously published data (LoPresti et al., 1995; Muller et al., 1997) and demonstrate that cultured oligodendroglial precursor cells and more mature oligodendrocytes express Tau.

Fyn is expressed by oligodendrocytes as shown previously (Umemori et al., 1994; Kramer et al., 1999; Osterhout et al., 1999). Fyn expression was observed in the cell body as well as in the tips of the processes and is coexpressed with Tau in the main processes and in the soma (Fig. $1 A, g, h$ ).

Many isoforms of Tau have been reported (Goedert et al., 1989). Western blots on oligodendroglial cell lysates showed that several isoforms of molecular weights between 45 and $66 \mathrm{kDa}$ can be detected (Fig. 1B). The oligodendroglial cell line Oli-neu appeared to express additional bands of higher molecular weight compared with primary oligodendrocytes; whether these are additional Tau isoforms or modifications (e.g., phosphorylation) of the isoforms present in primary cells is not clear.

\section{Fyn associates with Tau and Tubulin in primary oligodendrocytes}

Fyn is known to be tightly associated with other proteins in a functional signaling complex in $\mathrm{T}$ cells (Marie-Cardine et al., 1995; Marie-Cardine and Schraven, 1999; Marie-Cardine et al., 1999) and is associated with GPI-anchored adhesion molecules in oligodendrocytes in rafts (Kramer et al., 1999). Rafts can be collected as detergent-insoluble membrane domains from light fractions of sucrose density gradients (raft fractions), whereas other cellular components accumulate in bottom fractions (non-raft fractions). To determine downstream partners of Fyn in oligodendrocytes, immunoprecipitations with antibodies against Fyn were performed from raft and

unphosphorylated epitope and Tau-1 (lanes 3,4) recognizing a dephosphorylated serine at aa 199 (human nomenclature). Several isoforms are detected by both antibodies running between 45 and $65 \mathrm{kDa}$. Oli-neu cells may express additional isoforms compared with primary oligodendrocytes, or alternatively the isoforms are subjected to different posttranslational modifications. $w b$, Western blot. 


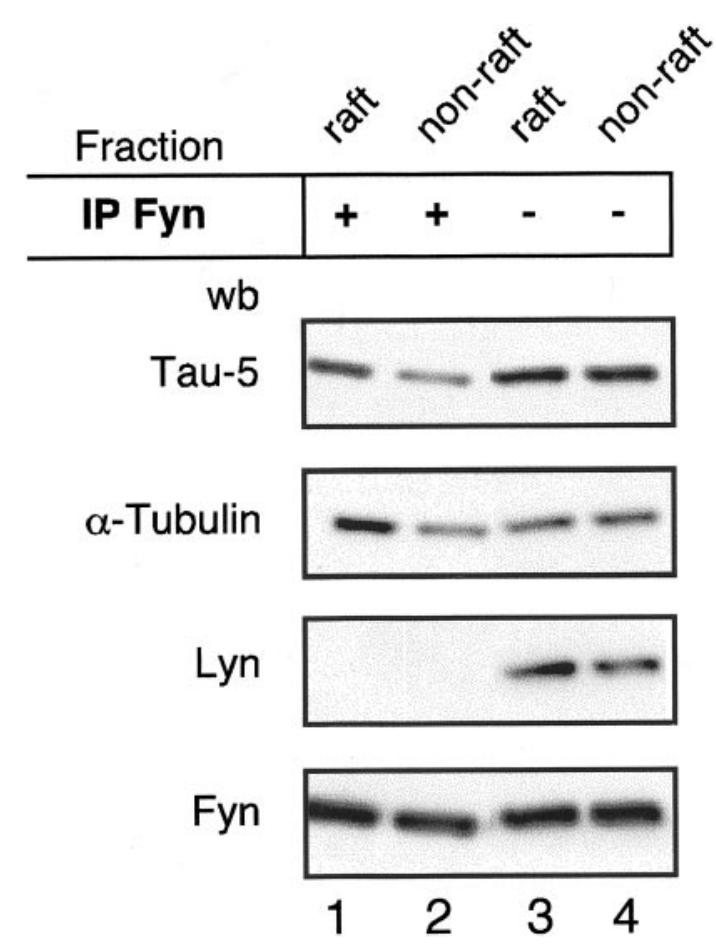

Figure 2. Fyn is associated with Tau and Tubulin in primary oligodendrocytes. Raft fractions and bottom gradient fractions of sucrose density gradients from primary oligodendrocytes were subjected to immunoprecipitation (IP) using antibodies to Fyn followed by SDSPAGE (lanes 1,2) or were analyzed directly by SDS-PAGE (lanes 3, 4) followed by Western blot $(w b)$ analysis using monoclonal antibodies against Fyn, Lyn, Tau, and $\alpha$-Tubulin. Fyn associates with Tau and $\alpha$-Tubulin in the raft fraction as well as in the bottom gradient fraction. Lyn, which is also found in the raft fraction (Lyn, lane 3), is not associated with this complex, either in the raft fraction (lane 1) or in the non-raft fraction (lane 2).

non-raft fractions and assayed by Western blot for coprecipitating candidate proteins (Fig. 2, lanes 1,2). Tau and $\alpha$-Tubulin were associated with the Fyn immunoprecipitates from both raft and non-raft fractions (Fig. 2). These interactions were resistant to high-stringency washing. Lyn (another Src family member) did not coprecipitate with Fyn (Fig. 2, lanes 1, 2), although it is present in total raft fractions (and also non-raft fractions; lanes 3, 4 ). This demonstrates that Fyn interacts in a specific complex with Tau and Tubulin. Vice versa, Tau immunoprecipitates from total lysates of primary oligodendrocytes also contained Fyn (data not shown).

\section{The Fyn SH3 and SH2 domains are sites of interaction with cytoskeletal proteins}

To analyze the Fyn-Tau and Fyn-Tubulin interaction in more detail and to identify the regions of Fyn that are involved, precipitation assays were performed using GST fusion proteins of the Fyn-SH2 and Fyn-SH3 protein interaction domains. The Western blot analysis of these precipitations with antibodies against Tau or Tubulin revealed that Tau binds specifically to the GST-Fyn-SH3 fusion protein, whereas $\alpha$-Tubulin binds to both GST-Fyn-SH3 and GST-Fyn-SH2 fusion proteins (Fig. 3). The binding is specific for the Fyn-SH3 domain because neither Tau nor $\alpha$-Tubulin binds to a GST fusion protein of the Amphiphysin-SH3 domain or GST alone (Fig. 3).

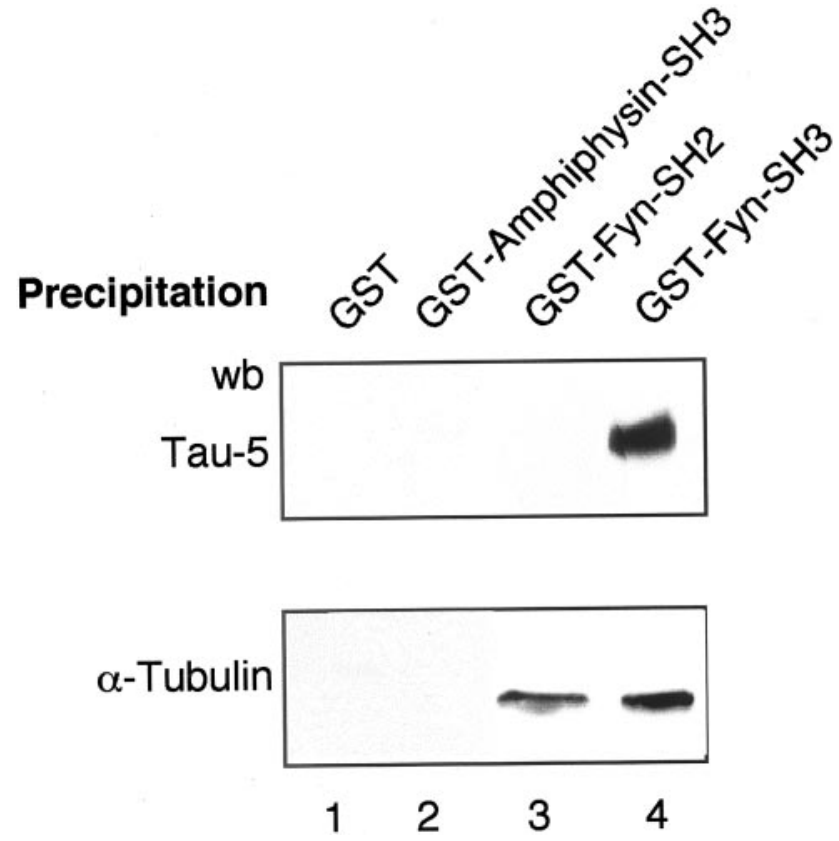

Figure 3. The $\mathrm{SH} 3$ and $\mathrm{SH} 2$ domains of Fyn interact with cytoskeletal proteins. Primary oligodendrocyte lysates were incubated with the different GST-fusion proteins and subjected to SDS-PAGE followed by Western blot analysis $(w b)$. Tau precipitates specifically with fusion proteins containing the SH3 domain of Fyn (lane 4); $\alpha$-Tubulin precipitates with the fusion proteins containing the $\mathrm{SH} 2$ or SH3 domain of Fyn (lanes 3, 4). Neither Tau nor $\alpha$-Tubulin binds to the SH3 domain of Amphiphysin (lane 2) or to GST alone (lane 1).

\section{Reduction of process number and process length in oligodendroglial cells after expression of a Fyn-binding Tau deletion protein}

We subsequently addressed the function of the Fyn-Tau interaction in living cells. Previous studies (Lee et al., 1998) had delineated the last of seven PXXP motives on Tau as the functional and sufficient Fyn-SH3 binding motif. We thus generated two Tau deletion mutant cDNA constructs by RT-PCR (Fig. 4A): one dominant negative construct (+PXXP; amino acid 1-227 of rat Tau), which should disrupt the endogenous Tau-Fyn interaction when overexpressed in cells, and a control construct (-PXXP; amino acids 1-223 of rat Tau) lacking the Fyn binding motif, which should not interfere with the Fyn-Tau interaction. Both constructs were tagged at the $\mathrm{N}$ terminus with a myc epitope to allow discrimination of the mutant protein from endogenous Tau. To demonstrate that the constructs function as expected, Oli-neu cells were transfected with the Tau deletion constructs, and the truncated myc Tau proteins were immunoprecipitated from metabolically labeled cells using anti-myc antibodies. As expected, endogenous Fyn coimmunoprecipitates with the + PXXP Tau protein, whereas it does not coprecipitate with -PXXP Tau (Fig. 4B). The transfection efficiency and expression level of each cDNA construct within the analyzed cells were equal, as shown by anti-myc Western blots on an equal number of cells (Fig. 4B, bottom panel). Myc precipitates of Oli-neu cells that were transfected with the +PXXP construct contained substantial Fyn kinase activity evidenced by autophosphorylation of Fyn in a kinase assay, whereas myc precipitates from cells transfected with the - PXXP construct or vector alone $(M O C K)$ did not (Fig. 4C, lanes 1-3). Active Fyn kinase is also immunoprecipitated with endogenous Tau from lysates of untransfected cells 
Figure 4. Tau deletion protein $+\mathrm{PXXP}$ bearing the Fyn binding motif binds to active Fyn. $A$, Design of the two rat Tau deletion mutants and model of action. $a$, -PXXP (aa 1-223), lacking the Fyn SH3 binding motif on Tau; $b$, + PXXP (aa 1-227), including the Fyn SH3 binding motif $(P X X P)$. Both constructs carry a myc tag at the $\mathrm{N}$ terminus. When overexpressed in oligodendroglial cells, the + PXXP Tau protein competes with endogenous Tau for Fyn binding. Because the +PXXP Tau protein is lacking the microtubuli $(M T)$ binding domain, the Fyn-Tau-Tubulin cascade is disrupted (b). In contrast, when the - PXXP control protein is overexpressed in these cells, the interaction cascade is preserved (a). $B$, Immunoprecipitation of radiolabeled Oli-neu cells with antibodies to myc. Oli-neu cells expressing either the + PXXP or - PXXP Tau protein were metabolically labeled with ${ }^{35} \mathrm{~S}$-methionine/cysteine and subjected to immunoprecipitation $(I P)$ with antibodies against myc followed by SDS-PAGE and Phosphoimager analysis. From cells expressing the + PXXP construct, a signal for Fyn at $59 \mathrm{kDa}$ is seen (top panel, arrow, lane 1). From cells expressing the - PXXP construct, no signal is seen (lane 2). Equal numbers of transfected cells were loaded on SDS-PAGE and analyzed by Western blot $(w b)$ with antibodies against myc (bottom panel), demonstrating a similar expression level of each Tau mutant. $C$, Kinase assays on the myc immunoprecipitates. Oli-neu cells were transiently transfected with + PXXP (lane 1), -PXXP (lane 2), or empty vector (MOCK; lane 3) and were subjected to immunoprecipitation with antibodies to myc. As a control, untransfected Oli-neu cells were subjected to immunoprecipitation with antibodies to Tau (lane 4) and Fyn (lane 5). An in vitro kinase assay was performed on the precipitates followed by

SDS-PAGE and autoradiography. A strong signal for phosphorylated and thus active Fyn is present in the myc precipitates from cells expressing the + PXXP construct (lane 1) and in the Tau immunoprecipitates (lane 4).

(lane 4). In conclusion, + PXXP Tau binds Fyn in the transfected cells and is thus likely to act as a competitor of the endogenous Tau-Fyn interaction.

Each of the deletion constructs was cotransfected with an EGFP plasmid (15:1 ratio) in Oli-neu cells or primary oligodendrocytes to facilitate visualization of the transfected cells. Staining of fixed cells with myc antibodies confirmed that every EGFPpositive cell also expressed the truncated myc Tau protein (data not shown).

The myc Tau overexpressing cells were analyzed by measuring the number and length of the cellular processes. In Oli-neu cells, the number of processes of +PXXP Tau overexpressing cells was reduced compared with cells overexpressing - PXXP Tau (Fig. $5 A, a)(p<0.0001)$. Analysis of the process revealed that the + PXXP overexpressing cells have shorter processes (reduction of $16 \%$ ) compared with - PXXP overexpressing cells (Fig. 5A, $b$ ) $(p=<0,0001)$. In transfected primary oligodendrocytes the effects were even more striking. The process length of +PXXP expressing primary cells is reduced by $49 \%$ versus - PXXP expressing cells (Fig. 5B,b) $(p<0.0001)$. Untransfected control cells and MOCK transfected cells appeared similar to the -PXXP expressing cells. The reduction of process growth is most likely caused by the disruption of the Fyn-Tau interaction and not an inactivation of Fyn kinase, because Fyn activity is retained in + PXXP overexpressing cells (Fig. 4C).

In summary, Oli-neu cells as well as primary oligodendrocytes expressing the +PXXP Tau protein have fewer and shorter processes compared with cells expressing the -PXXP Tau. These results thus suggest that the Fyn-Tau interaction in oligodendroglial cells is important for the generation and elaboration of cellular processes.

\section{Inhibiting gsl synthesis and thus raft formation prevents process outgrowth of Oli-neu cells}

Because Fyn kinase activity linked to the cell adhesion molecule F3 is restricted to rafts in oligodendroglial cells, we studied the involvement of rafts in process outgrowth. We made use of the fungal toxin FB1, which inhibits sphingolipid synthesis (Merrill et al., 1993b) and completely abolishes the formation of rafts in oligodendroglial cells (Fig. 6A). 
a

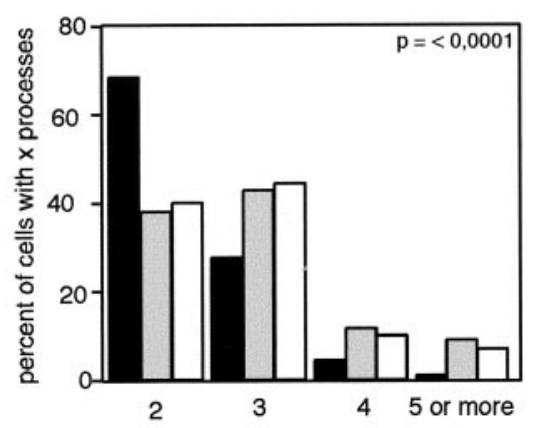

B

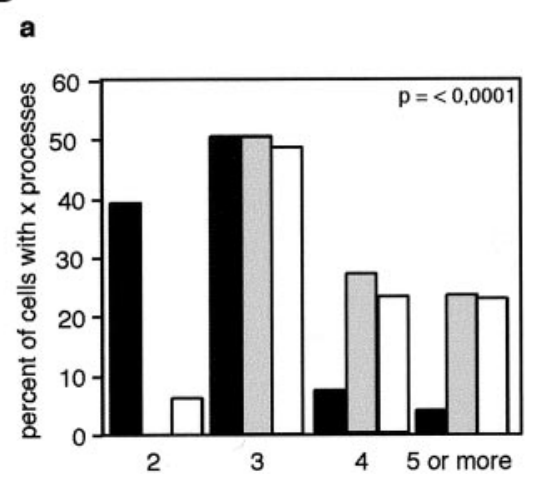

b

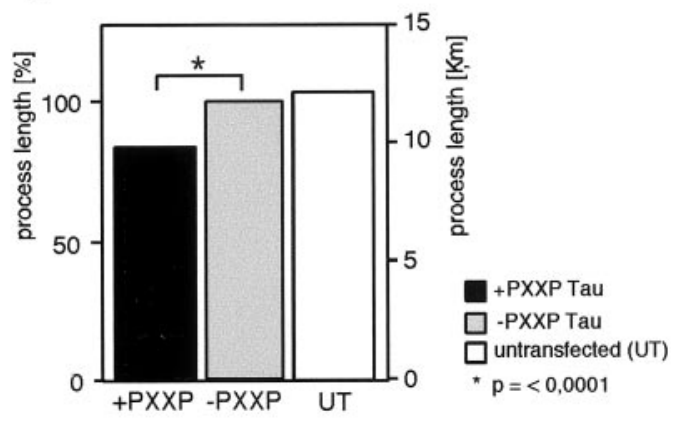

b

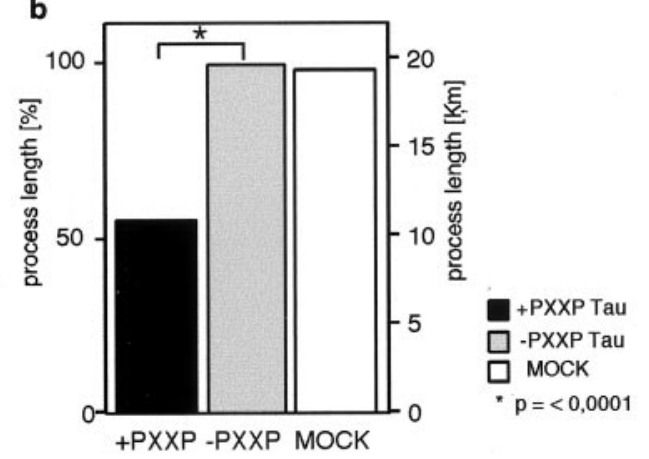

Figure 5. Inhibition of the interaction between Fyn and Tau decreases process number and process length in oligodendroglial cells. Oli-neu cells $(A)$ or primary oligodendrocytes $(B)$ were transfected with the Tau deletion constructs - PXXP and +PXXP and cultured for $1 \mathrm{~d}$. The process length and number of processes were analyzed. Processes longer than half the diameter of the cell soma were included in the measurements. Three individual experiments were performed, and the data were summarized and analyzed by the Mann-Whitney rank sum test. Olineu cells $(A, a ; p<0.0001)$ as well as primary oligodendrocytes $(B, a ; p<$ 0.0001 ) expressing the +PXXP construct have fewer processes compared with the -PXXP transfected controls. The process length of +PXXP transfected Olineu cells is reduced by $16 \%(A, b ; p<$ 0.0001 ), and the process length of + PXXP transfected primary oligodendrocytes is reduced by $49 \%(B, b ; p<$ 0.0001) compared with - PXXP expressing cells and untransfected $(U T)$ or MOCK transfected cells.
When primary oligodendrocytes were cultured in the presence of FB1 for several days, the GPI-anchored protein adhesion protein neural cell adhesion molecule (NCAM) 120, which is normally raft associated (Kramer et al., 1997, 1999), was absent from light gradient fractions (Fig. 6 $A, a$ ). FB1-treated cells lack gsl, leading to a complete absence of raft lipids, including cholesterol, from light gradient fractions (Fig. 6 $A, b$ ). Incubation of Oli-neu cells with FB1 similarly inhibits raft formation, and thus Tau protein is no longer found in light gradient fractions (Fig. $6 B, a)$. Process outgrowth was strongly diminished in Oli-neu cells cultured for $5 \mathrm{~d}$ in FB1, including one passage (Fig. 6B,c). This effect was reversible: $48 \mathrm{hr}$ after removal of FB1 from the medium allowing resynthesis of gsl, the cells had reestablished processes (Fig. 6B,d), demonstrating that FB1 was not toxic to the cells. In conclusion, gsls are essential for process outgrowth of oligodendrocytes; furthermore, the results suggest that Fyn-Tau associations occurring in the raft compartment may be a contributing factor.

\section{DISCUSSION}

Myelination of axons by oligodendrocytes is a multistep process. After initial recognition of the axon by the glial process, wrapping necessitates the coordination of myelin membrane generation and directed process outgrowth accompanied by reorganization of the cytoskeleton (Wilson and Brophy, 1989; Pfeiffer et al., 1993; Kramer et al., 1997, 2001; Song et al., 2001a). In the present study we have shown that the interaction of the Src-family tyrosine kinase Fyn and the microtubule-binding protein Tau is an important component of process formation by oligodendrocytes.

\section{Fyn activity is instructive for myelination}

Fyn kinase plays an important role in myelination: in myelin the activity peaks at early postnatal stages concomitant with the initiation of myelination in large areas of the brain (Umemori et al., 1994; Kramer et al., 1999). Transgenic knock-in mice expressing a Fyn protein with a nonfunctional kinase domain (Sperber et al., 2001) exhibit a hypomyelinated phenotype similar to Fyndeficient mice (Umemori et al., 1994), suggesting that the kinase activity of Fyn is important. However, both groups of mice still synthesize some myelin, suggesting the involvement of an alternative but less efficient signal transduction pathway. Previously, we showed that Fyn is closely associated with the GPI-anchored cell adhesion molecules F3/Contactin and NCAM 120 in oligodendrocyte rafts and could be activated by ligation of F3 (Kramer et al., 1999). In addition, Fyn was identified as a downstream partner of L-MAG, and Fyn can be activated via antibodymediated cross-linking of MAG in transfected COS cells (Umemori et al., 1994). However, MAG/Fyn double-deficient mice have a more severe phenotype than the single knock-outs, indicating that MAG and Fyn might also act independently in myelination (Biffiger et al., 2000).

Recent studies have shown that oligodendrocyte progenitor cells and more mature cells express active Fyn kinase (Kramer et al., 1999; Osterhout et al., 1999) and that Fyn kinase activity promotes oligodendrocyte process formation in vitro (Osterhout et al., 1999; Sperber et al., 2001). Inhibitors of Fyn kinase and expression of dominant negative Fyn inhibited process outgrowth in cultured oligodendrocytes (Osterhout et al., 1999). Here, we have addressed the downstream interacting partners of Fyn in oligodendrocytes.

\section{In oligodendrocytes, Fyn interacts with Tau and Tubulin}

The microtubule-binding protein Tau has been identified as a binding partner for Fyn in neuroblastoma cells (Lee et al., 1998). Oligodendrocytes, in particular progenitor cells, and more mature cells express Tau in vitro (LoPresti et al., 1995; Muller et al., 1997; 
A

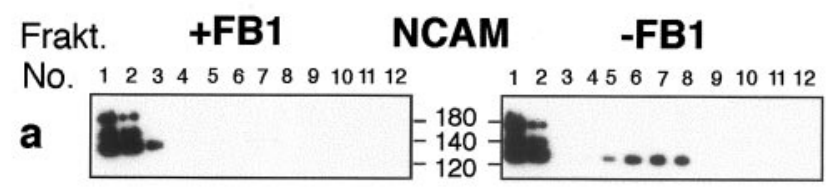

b

\section{Frakt. $\quad$ +FB1}

No. 1234556789101112

PL

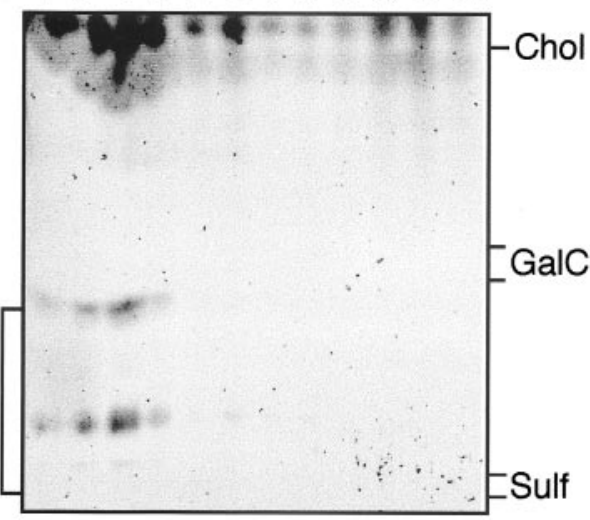

Frakt.

-FB1

No.1 $2 \quad 3 \quad 45567789101112$

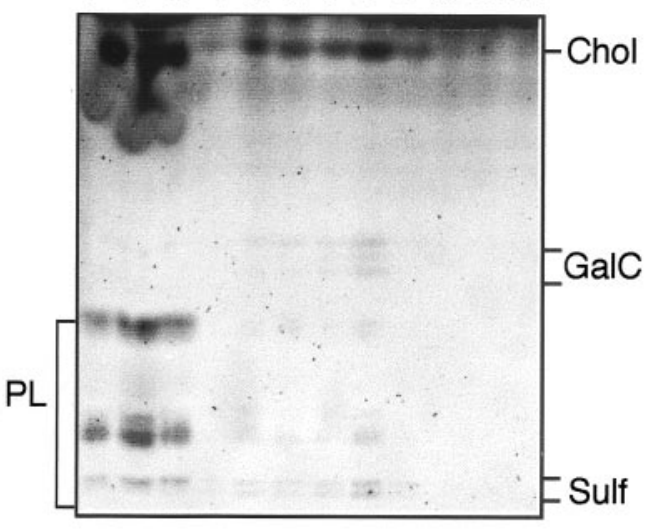

B
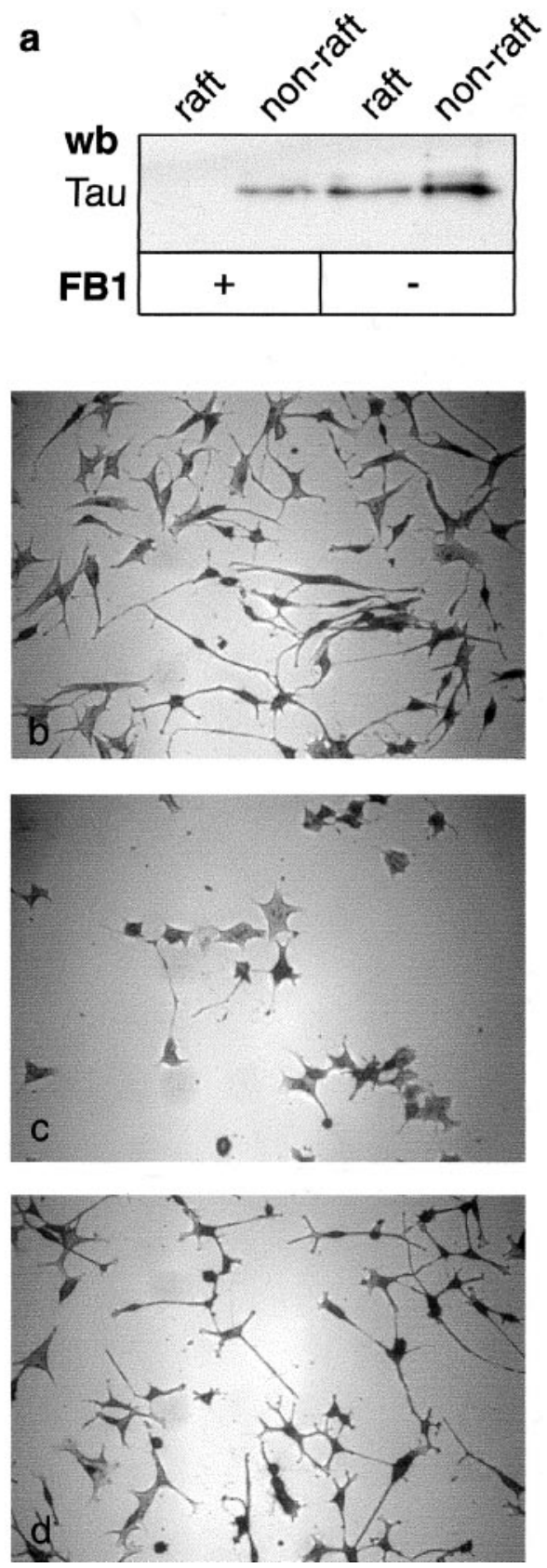

Figure 6. Inhibition of glycosphingolipid synthesis prevents raft formation in oligodendrocytes and inhibits process growth in Oli-neu cells. $A$, Distribution of NCAM protein and lipids on gradients of FB1-treated oligodendrocytes. $a$, Primary oligodendrocytes were cultured for $5 \mathrm{~d}$ with Fumonisin B1 (FB1) and fractionated on sucrose density gradients. The fractions were collected and analyzed by Western blot with antibodies against $\operatorname{NCAM}(a)$ or were subjected to lipid extraction and analyzed by TLC $(b)$. Fraction (Frakt.) 1 is the bottom gradient fraction. In cells cultured in the presence of FB1, the GPI-anchored NCAM form NCAM 120 is no longer localized in the raft fraction as is seen in the untreated cells $(a)$, but is entirely present in the non-raft fraction. $b$, FB1-treated primary oligodendrocytes do not synthesize sphingolipids. No signal for galactocerebroside (GalC) or Sulfatide (Sulf) can be detected in lipids of FB1-treated cells in comparison with control cells. Chol, Cholesterol; $P E$, phosphatidylethanolamine; SM, sphingomyelin. $B$, FB1 inhibits process outgrowth of Oli-neu cells. $a$, Oli-neu cells were cultured for $3 \mathrm{~d}$ with FB1 (+) or without FB1 (-). Raft fractions and non-raft fractions were collected from sucrose density gradients and subjected to SDS-PAGE followed by Western blot analysis with antibodies against Tau. Culture in FB1 results in the absence of Tau from low density gradient fractions; in untreated cells Tau is localized in rafts in these gradient fractions. Oli-neu cells were cultured in the absence of $(b)$ or in the presence of (c) $50 \mu \mathrm{m}$ FB1 for several days (see Material and Methods). After $5 \mathrm{~d}$ in culture in FB1 including one passage, the cells are almost lacking processes $(c)$. Nevertheless they are still alive, because after further culture $(2 \mathrm{~d})$ in the absence of FB1 the cells recover and regenerate processes $(d)$.

Richter-Landsberg and Gorath, 1999; this study) and in vivo (LoPresti et al., 1995; Song et al., 2001b). Tau is expressed mainly in the cell soma and in the large processes (LoPresti et al., 1995; Muller et al., 1997; Song et al., 2001a; this study). Several Tau isoforms are expressed in vivo (Goedert et al., 1991) and by oligodendrocytes in vitro (Richter-Landsberg and Gorath, 1999; LoPresti et al., 2001). The function of the different isoforms is still unelucidated, but all contain the PXXP SH3-binding motif. We found that Fyn is associated with Tau and Tubulin in oligodendrocytes. These interactions are of high affinity, because they resist stringent washing. 


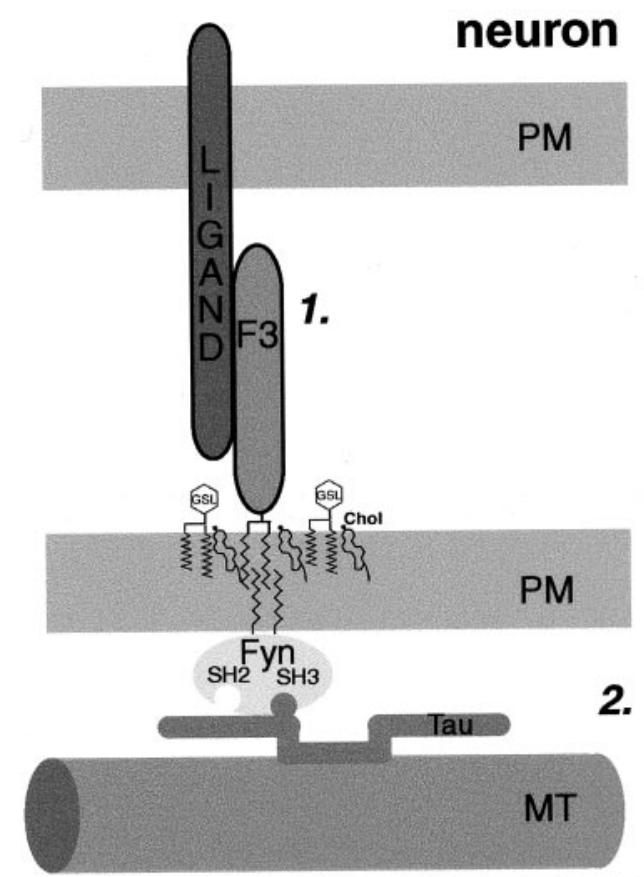

\section{oligodendrocyte}

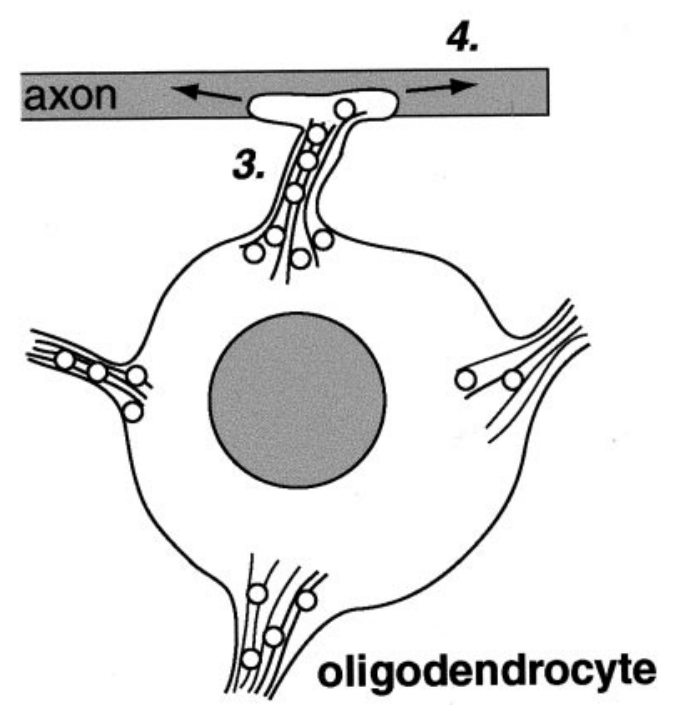

Figure 7. Proposed model of the role of Fyn and Tau in myelination. During development, oligodendrocyte processes initiate contact with an axon. The interaction of adhesion molecules such as F3 and signaling events in both cells are necessary (1.). Ligation of F3 by an axonal ligand activates Fyn in raft microdomains leading to increased binding of Tau. Microtubuli (MT) are recruited to the area of contact (2.). Vesicular transport to the contact site is facilitated (3.), and insertion of vesicles containing myelin-specific lipid and proteins promotes further internodal process elongation along and around the axon (4.). PM, Plasma membrane; GSL, glycosphingolipid; $\mathrm{Chol}$, cholesterol.

We show that Fyn binds to Tau in oligodendrocyte lysates by association of the Fyn-SH3 domain with the PXXP motif on Tau, as reported in neuroblastoma cells (Lee et al., 1998), whereas $\alpha$-Tubulin binds to both the Fyn SH2 and SH3 domains. The interaction of Tubulin with the SH2 domain of Fyn has also been described in T lymphocytes (Marie-Cardine et al., 1995). Tau and
Tubulin do not bind to all SH3 domains, but the binding is specific for the SH3 domain of Fyn, because neither Tau nor Tubulin bind to the SH3 domain of Amphiphysin. In Src family kinases, the $\mathrm{SH} 2$ and $\mathrm{SH} 3$ domains together with the regulatory tail play a central role in regulation of the kinase. In the inactive state, the $\mathrm{SH} 2$ domain is bound to the regulatory tail, and the $\mathrm{SH} 3$ domain interacts with sequences in the catalytic domain as well as in the linker region between the SH3 and SH2 domains (Pawson, 1997; Sicheri and Kuriyan, 1997; Xu et al., 1997; Young et al., 2001) (for review, see Thomas and Brugge, 1997). On dephosphorylation of a tyrosine in the regulatory tail, the intramolecular interactions are disrupted, and the full kinase activity results from autophosphorylation of a tyrosine residue within the catalytic domain. The kinase structure opens up, and binding of other proteins via the $\mathrm{SH} 3$ and SH2 domains is now possible (Thomas and Brugge, 1997). Thus, activation of Fyn is required for binding to interacting partners via the Fyn $\mathrm{SH} 2$ and $\mathrm{SH} 3$ domains. The molecular trigger for Fyn activation in culture in the absence of neurons is unelucidated but must entail interactions with the culture substrate.

\section{Overexpression of a Tau deletion mutant inhibits oligodendroglial process formation, most likely by perturbing the Tau-Fyn interaction}

We expressed two Tau deletion mutants in Oli-neu cells and primary oligodendrocytes. Tau contains seven putative PXXP SH3 binding motives (Cheadle et al., 1994; Sparks et al., 1994) in the amino terminal proline-rich domain, but only the last motif is the major Fyn SH3 binding site (Lee et al., 1998). The deletion constructs were designed such that one construct contained the Fyn recognition motif (+PXXP), enabling competition with endogenous Tau for binding to Fyn, whereas the control construct lacked this domain (-PXXP). Both constructs lacked the microtubule-binding region. In transfected cells, the +PXXP construct thus should interfere with endogenous Tau linking Fyn and microtubules (Fig. 4A). We demonstrated that the +PXXP Tau protein indeed interacts with endogenous Fyn and that the bound Fyn retains substantial kinase activity. Oli-neu cells as well as primary oligodendrocytes expressing + PXXP Tau exhibited a reduced number of processes and a reduction in process length. Our results suggest that Fyn activity not only is important for process formation as shown by others (Osterhout et al., 1999; Sperber et al., 2001), but that the interaction of Tau and Fyn in oligodendrocytes is a central element. Expression of a Tau deletion mutant that binds Fyn and should thus disrupt this association leads to reduced process number and process length, although Fyn is still active.

Tau regulates the assembly and stability of microtubules in neurons (for review, see Brandt, 1996). In the Taiep mutant rat, the polarized orientation of microtubules (Lunn et al., 1997) is abnormal, and Tau protein accumulates in the cell body and processes of oligodendrocytes, resulting in an intracellular accumulation of myelin proteins, hypomyelination, and progressive demyelination (Song et al., 2001a,b). This study highlights the interplay of Tau and microtubules and the importance of microtubules in the transport of vesicles containing myelin components to the forming sheath.

\section{Interaction of Tau and Tubulin with Fyn in raft and non-raft compartments}

Rafts are gsl- and cholesterol-rich microdomains that form in the trans-Golgi network. They play an instructive role in sorting proteins and lipids to specific cellular compartments and act as 
signal transduction platforms via selective inclusion/exclusion of signaling components (for review, see Harder and Simons, 1997; Simons and Ikonen, 1997; Brown and London, 2000; Trotter et al., 2000; Ikonen, 2001). Active Fyn is present in both raft and non-raft fractions (Kramer et al., 1999), and as we show here, it can thus associate with binding partners such as Tau and Tubulin independent of raft association. The Tau deletion mutant would thus interfere with Fyn-Tau interactions inside and outside rafts. However, activation of Fyn kinase mediated by ligation of the F3 cell adhesion molecule occurs exclusively in rafts (Kramer et al., 1999). Stimulation of Fyn activity in the raft domain would lead to an increased capacity of Fyn in rafts to bind to downstream partners including Tau and Tubulin. Cytoskeletal elements would thus be recruited to raft domains after ligation of raft components. In lymphocytes, the actin cytoskeleton undergoes local rearrangement after ligation of raft components such as CD59 (Harder and Simons, 1999), IgE-receptor 1 (Holowka et al., 2000; Foger et al., 2001), and the $\mathrm{T}$ cell receptor at the immunological synapse (for review, see Viola and Lanzavecchia, 1999).

\section{Disruption of rafts reduces process outgrowth in oligodendrocytes}

The integrity of rafts can be disrupted by manipulation of the lipid composition either by removal of cholesterol or inhibition of the sphingolipid synthesis using fungal toxins such as FB1 (Cerneus et al., 1993; Merrill et al., 1993a; Klein et al., 1995; Stevens and Tang, 1997; Ilangumaran and Hoessli, 1998). Inhibition of the sphingolipid synthesis in oligodendroglial cells prevents the formation of rafts and reduces process formation. The reduction of the process outgrowth caused by FB1 is comparable to the effect seen with the Tau deletion mutant. Recruitment of Tau (and Tubulin) to rafts after Fyn activation would explain a role of rafts in process formation. Several studies have shown that inhibition of sphingolipid synthesis in neurons inhibits protein sorting and axonal and dendritic growth (Harel and Futerman, 1993; Futerman et al., 1998; Ledesma et al., 1998, 1999; Schwarz and Futerman, 1998). Thus rafts may play an important role in process formation in oligodendrocytes and neurons.

\section{Rafts as signal transduction platforms and sites of cytoskeletal reorganization during initial glial-axon interaction?}

Several signaling pathways are likely to cooperate in the initiation of myelination (Biffiger et al., 2000), including raft-independent signaling via MAG (Meyer-Franke and Barres, 1994; Montag et al., 1994) and raft-dependent signaling via F3 (Kramer et al., 1999). Oligodendroglial rafts are enriched in the GPI-anchored proteins NCAM 120 and F3. They may be instrumental in orchestrating the initial axon-glial contact and may act as signaling platforms and local sites of cytoskeletal reorganization. We suggest that in vivo, signaling caused by ligation of glial F3 via an axonal ligand such as L1 activates oligodendroglial Fyn in the rafts, which then recruits Tau promoting process outgrowth and strengthening the initial axonal-glial contact. Local reorganization of the cytoskeleton such as the polarized organization of the microtubule network toward the contact site subsequently facilitates the directed transport of membrane vesicles containing myelin lipids and proteins to the expanding internode (Fig. 7).

\section{REFERENCES}

Biffiger K, Bartsch S, Montag D, Aguzzi A, Schachner M, Bartsch U (2000) Severe hypomyelination of the murine CNS in the absence of myelin-associated glycoprotein and fyn tyrosine kinase. J Neurosci 20:7430-7437.
Binder LI, Frankfurter A, Rebhun LI (1985) The distribution of tau in the mammalian central nervous system. J Cell Biol 101:1371-1378.

Bligh EG, Dyer WJ (1957) A rapid method of total lipid extraction and purification. Can J Biochem Physiol 37:911-917.

Brandt R (1996) The tau proteins in neuronal growth and development. Front Biosci 1:d118-130.

Brandt R, Leger J, Lee G (1995) Interaction of tau with the neural plasma membrane mediated by tau's amino-terminal projection domain. J Cell Biol 131:1327-1340.

Brown DA, London E (2000) Structure and function of sphingolipidand cholesterol-rich membrane rafts. J Biol Chem 275:17221-17224.

Cerneus DP, Ueffing E, Posthuma G, Strous GJ, van der Ende A (1993) Detergent insolubility of alkaline phosphatase during biosynthetic transport and endocytosis. Role of cholesterol. J Biol Chem 268:3150-3155.

Cheadle C, Ivashchenko Y, South V, Searfoss GH, French S, Howk R, Ricca GA, Jaye M (1994) Identification of a Src SH3 domain binding motif by screening a random phage display library. J Biol Chem 269:24034-24039.

Foger N, Marhaba R, Zoller M (2001) Involvement of CD44 in cytoskeleton rearrangement and raft reorganization in $\mathrm{T}$ cells. J Cell Sci 114:1169-1178

Futerman AH, Boldin S, Brann AB, Schwarz A, Zisling R (1998) Regulatory roles for sphingolipids in the growth of polarized neurons. Ann NY Acad Sci 845:176-187.

Goedert M, Spillantini MG, Potier MC, Ulrich J, Crowther RA (1989) Cloning and sequencing of the cDNA encoding an isoform of microtubule-associated protein tau containing four tandem repeats: differential expression of tau protein mRNAs in human brain. EMBO J 8:393-399.

Goedert M, Crowther RA, Garner CC (1991) Molecular characterization of microtubule-associated proteins tau and MAP2. Trends Neurosci 14:193-199.

Harder T, Simons K (1997) Caveolae, DIGs, and the dynamics of sphingolipid-cholesterol microdomains. Curr Opin Cell Biol 9:534-542.

Harder T, Simons K (1999) Clusters of glycolipid and glycosylphosphatidylinositol-anchored proteins in lymphoid cells: accumulation of actin regulated by local tyrosine phosphorylation. Eur J Immunol 29:556-562.

Harel R, Futerman AH (1993) Inhibition of sphingolipid synthesis affects axonal outgrowth in cultured hippocampal neurons. J Biol Chem 268:14476-14481.

Holowka D, Sheets ED, Baird B (2000) Interactions between Fc(epsilon)RI and lipid raft components are regulated by the actin cytoskeleton. J Cell Sci 113:1009-1019.

Ikonen E (2001) Roles of lipid rafts in membrane transport. Curr Opin Cell Biol 13:431-437.

Ilangumaran S, Hoessli DC (1998) Effects of cholesterol depletion by cyclodextrin on the sphingolipid microdomains of the plasma membrane. Biochem J 335:433-440.

Jung M, Kramer E, Grzenkowski M, Tang K, Blakemore W, Aguzzi A Khazaie K, Chlichlia K, von Blankenfeld G, Kettenmann H, Trotter JT (1995) Lines of murine oligodendroglial precursor cells immortalized by an activated neu tyrosine kinase show distinct degrees of interaction with axons in vitro and in vivo. Eur J Neurosci 7:1245-1265.

Klein U, Gimpl G, Fahrenholz F (1995) Alteration of the myometrial plasma membrane cholesterol content with beta-cyclodextrin modulates the binding affinity of the oxytocin receptor. Biochemistry 34:13784-13793.

Koch T, Brugger T, Bach A, Gennarini G, Trotter J (1997) Expression of the immunoglobulin superfamily cell adhesion molecule F3 by oligodendrocyte-lineage cells. Glia 19:199-212.

Kramer EM, Koch T, Niehaus A, Trotter J (1997) Oligodendrocytes direct glycosyl phosphatidylinositol-anchored proteins to the myelin sheath in glycosphingolipid-rich complexes. J Biol Chem 272:8937-8945.

Kramer EM, Klein C, Koch T, Boytinck M, Trotter J (1999) Compartmentation of Fyn kinase with glycosylphosphatidylinositol-anchored molecules in oligodendrocytes facilitates kinase activation during myelination. J Biol Chem 274:29042-29049.

Kramer EM, Schardt A, Nave KA (2001) Membrane traffic in myelinating oligodendrocytes. Microsc Res Tech 52:656-671.

Ledesma MD, Simons K, Dotti CG (1998) Neuronal polarity: essential role of protein-lipid complexes in axonal sorting. Proc Natl Acad Sci USA 95:3966-3971.

Ledesma MD, Brugger B, Bunning C, Wieland FT, Dotti CG (1999) Maturation of the axonal plasma membrane requires upregulation of sphingomyelin synthesis and formation of protein-lipid complexes. EMBO J 18:1761-1771.

Lee G, Newman ST, Gard DL, Band H, Panchamoorthy G (1998) Tau interacts with src-family non-receptor tyrosine kinases. J Cell Sci 111:3167-3177.

LoPresti P, Szuchet S, Papasozomenos SC, Zinkowski RP, Binder LI (1995) Functional implications for the microtubule-associated protein 
tau: localization in oligodendrocytes. Proc Natl Acad Sci USA 92:10369-10373.

LoPresti P, Muma NA, DeVries GH (2001) Neu differentiation factor regulates Tau protein and mRNA in cultured neonatal oligodendrocytes. Glia 35:147-155.

Lunn KF, Baas PW, Duncan ID (1997) Microtubule organization and stability in the oligodendrocyte. J Neurosci 17:4921-4932.

Maas T, Eidenmuller J, Brandt R (2000) Interaction of tau with the neural membrane cortex is regulated by phosphorylation at sites that are modified in paired helical filaments. J Biol Chem 275:15733-15740.

Marie-Cardine A, Schraven B (1999) Coupling the TCR to downstream signalling pathways: the role of cytoplasmic and transmembrane adaptor proteins. Cell Signal 11:705-712.

Marie-Cardine A, Kirchgessner H, Eckerskorn C, Meuer SC, Schraven B (1995) Human T lymphocyte activation induces tyrosine phosphorylation of alpha-tubulin and its association with the $\mathrm{SH} 2$ domain of the p59fyn protein tyrosine kinase. Eur J Immunol 25:3290-3297.

Marie-Cardine A, Kirchgessner H, Schraven B (1999) Molecular alterations of the Fyn-complex occur as late events of human $\mathrm{T}$ cell activation. Eur J Immunol 29:1175-1187.

Merrill Jr AH, Wang E, Gilchrist DG, Riley RT (1993a) Fumonisins and other inhibitors of de novo sphingolipid biosynthesis. Adv Lipid Res 26:215-234.

Merrill AH, van Echten G, Wang E, Sandhoff K (1993b) Fumonisin B1 inhibits sphingosine (sphinganine) $N$-acyltransferase and de novo sphingolipid biosynthesis in cultured neurons in situ. J Biol Chem 268:27299-27306.

Meyer-Franke A, Barres B (1994) Axon myelination. Myelination without myelin-associated glycoprotein. Curr Biol 4:847-850.

Montag D, Giese KP, Bartsch U, Martini R, Lang Y, Bluthmann H, Karthigasan J, Kirschner DA, Wintergerst ES, Nave KA (1994) Mice deficient for the myelin-associated glycoprotein show subtle abnormalities in myelin. Neuron 13:229-246.

Muller R, Heinrich M, Heck S, Blohm D, Richter-Landsberg C (1997) Expression of microtubule-associated proteins MAP2 and tau in cultured rat brain oligodendrocytes. Cell Tissue Res 288:239-249.

Osterhout DJ, Wolven A, Wolf RM, Resh MD, Chao MV (1999) Morphological differentiation of oligodendrocytes requires activation of Fyn tyrosine kinase. J Cell Biol 145:1209-1218.

Pawson T (1997) New impressions of Src and Hck. Nature 385:582-585.

Pedraza L, Huang JK, Colman DR (2001) Organizing principles of the axoglial apparatus. Neuron 30:335-344.

Pfeiffer SE, Warrington AE, Bansal R (1993) The oligodendrocyte and its many cellular processes. Trends Cell Biol 3:191-197.

Richter-Landsberg C (2000) The oligodendroglia cytoskeleton in health and disease. J Neurosci Res 59:11-18.

Richter-Landsberg C, Gorath M (1999) Developmental regulation of alternatively spliced isoforms of mRNA encoding MAP2 and tau in rat brain oligodendrocytes during culture maturation. J Neurosci Res 56:259-270.

Schwarz A, Futerman AH (1998) Inhibition of sphingolipid synthesis, but not degradation, alters the rate of dendrite growth in cultured hippocampal neurons. Brain Res Dev Brain Res 108:125-130.

Sicheri F, Kuriyan J (1997) Structures of Src-family tyrosine kinases. Curr Opin Struct Biol 7:777-785.
Simons K, Ikonen E (1997) Functional rafts in cell membranes. Nature 387:569-572.

Smith D, Johnson K (1988) Single-step purification of polypeptides expressed in Escherichia coli as fusions with glutathione $S$-transferase. Gene 67:31-40.

Sommer I, Schachner M (1981) Monoclonal antibodies (O1 to O4) to oligodendrocyte cell surfaces: an immunocytological study in the central nervous system. Dev Biol 83:311-327.

Song J, Goetz BD, Baas PW, Duncan ID (2001a) Cytoskeletal reorganization during the formation of oligodendrocyte processes and branches. Mol Cell Neurosci 17:624-636.

Song J, Goetz BD, Kirvell SL, Butt AM, Duncan ID (2001b) Selective myelin defects in the anterior medullary velum of the Taiep mutant rat. Glia 33:1-11.

Sontheimer H, Trotter J, Schachner M, Kettenmann H (1989) Channel expression correlates with differentiation stage during the development of oligodendrocytes from their precursor cells in culture. Neuron 2:1135-1145.

Sparks AB, Quilliam LA, Thorn JM, Der CJ, Kay BK (1994) Identification and characterization of Src SH3 ligands from phage-displayed random peptide libraries. J Biol Chem 269:23853-23856.

Sperber B, McMorris F (2001) Fyn tyrosine kinase regulates oligodendroglial cell development but is not required for morphological differentiation of oligodendrocytes. J Neurosci Res 63:303-312.

Sperber BR, Boyle-Walsh EA, Engleka MJ, Gadue P, Peterson AC, Stein PL, Scherer SS, McMorris FA (2001) A unique role for Fyn in CNS myelination. J Neurosci 21:2039-2047.

Stevens VL, Tang J (1997) Fumonisin B1-induced sphingolipid depletion inhibits vitamin uptake via the glycosylphosphatidylinositolanchored folate receptor. J Biol Chem 272:18020-18025.

Thomas SM, Brugge JS (1997) Cellular functions regulated by Src family kinases. Annu Rev Cell Dev Biol 13:513-609.

Trotter J, Bitter-Suermann D, Schachner M (1989) Differentiationregulated loss of the polysialylated embryonic form and expression of the different polypeptides of the neural cell adhesion molecule by cultured oligodendrocytes and myelin. J Neurosci Res 22:369-383.

Trotter J, Klein C, Kramer E-M (2000) GPI-anchored proteins, glycosphingolipid-rafts: platforms for adhesion, signaling. The Neuroscientist 6:271-284.

Umemori H, Sato S, Yagi T, Aizawa S, Yamamoto T (1994) Initial events of myelination involve Fyn tyrosine kinase signalling. Nature 367:572-576.

Viola A, Lanzavecchia A (1999) T-cell activation and the dynamic world of rafts. Apmis 107:615-623.

Wilson R, Brophy PJ (1989) Role for the oligodendrocyte cytoskeleton in myelination. J Neurosci Res 22:439-448.

Xu W, Harrison SC, Eck MJ (1997) Three-dimensional structure of the tyrosine kinase c-Src. Nature 385:595-602.

Young MA, Gonfloni S, Superti-Furga G, Roux B, Kuriyan J (2001) Dynamic coupling between the $\mathrm{SH} 2$ and $\mathrm{SH} 3$ domains of c-Src and Hck underlies their inactivation by $\mathrm{C}$-terminal tyrosine phosphorylation. Cell 105:115-126.

Zisch AH, D'Alessandri L, Amrein K, Ranscht B, Winterhalter KH, Vaughan L (1995) The glypiated neuronal cell adhesion molecule contactin/F11 complexes with src-family protein tyrosine kinase Fyn. Mol Cell Neurosci 6:263-279. 